\title{
Characterization of stony soils' hydraulic conductivity using laboratory and numerical experiments
}

\author{
Eléonore Beckers $^{1}$, Mathieu Pichault ${ }^{1,2}$, Wanwisa Pansak ${ }^{3}$, Aurore Degré ${ }^{1}$, and Sarah Garré ${ }^{2}$ \\ ${ }^{1}$ Université de Liège, Gembloux Agro-Bio Tech, UR Biosystems Engineering, Passage des déportés 2, \\ 5030 Gembloux, Belgium \\ ${ }^{2}$ Université de Liège, Gembloux Agro-Bio Tech, UR TERRA, Passage des déportés 2, \\ 5030 Gembloux, Belgium \\ ${ }^{3}$ Naresuan University, Department of Agricultural Science, 65000 Phitsanulok, Thailand
}

Correspondence to: Sarah Garré (sarah.garre@ulg.ac.be)

Received: 13 October 2015 - Published in SOIL Discuss.: 29 October 2015

Revised: 6 July 2016 - Accepted: 19 July 2016 - Published: 12 August 2016

\begin{abstract}
Determining soil hydraulic properties is of major concern in various fields of study. Although stony soils are widespread across the globe, most studies deal with gravel-free soils, so that the literature describing the impact of stones on the hydraulic conductivity of a soil is still rather scarce. Most frequently, models characterizing the saturated hydraulic conductivity of stony soils assume that the only effect of rock fragments is to reduce the volume available for water flow, and therefore they predict a decrease in hydraulic conductivity with an increasing stoniness. The objective of this study is to assess the effect of rock fragments on the saturated and unsaturated hydraulic conductivity. This was done by means of laboratory experiments and numerical simulations involving different amounts and types of coarse fragments. We compared our results with values predicted by the aforementioned predictive models. Our study suggests that it might be ill-founded to consider that stones only reduce the volume available for water flow. We pointed out several factors of the saturated hydraulic conductivity of stony soils that are not considered by these models. On the one hand, the shape and the size of inclusions may substantially affect the hydraulic conductivity. On the other hand, laboratory experiments show that an increasing stone content can counteract and even overcome the effect of a reduced volume in some cases: we observed an increase in saturated hydraulic conductivity with volume of inclusions. These differences are mainly important near to saturation. However, comparison of results from predictive models and our experiments in unsaturated conditions shows that models and data agree on a decrease in hydraulic conductivity with stone content, even though the experimental conditions did not allow testing for stone contents higher than $20 \%$.
\end{abstract}

\section{Introduction}

Determining soil hydraulic properties is of primary importance in various fields of study such as soil physics, hydrology, ecology, and agronomy. Information on hydraulic properties is essential to model infiltration and runoff, to quantify groundwater recharge, to simulate the movement of water and pollutants in the vadose zone, etc. (Bouwer and Rice, 1984). Most unsaturated flow studies characterize the hydraulic properties of the fine fraction (particles smaller than $2 \mathrm{~mm}$ in diameter) of supposedly uniform soils only (Bouwer and Rice, 1984; Buchter et al., 1994; Gusev and Novák, 2007). Nevertheless, in reality, soils are heterogeneous media and may contain coarse inclusions (stones) of various sizes and shapes.

Stony soils are widespread across the globe (Ma and Shao, 2008) and represent a significant part of the agricultural land (Miller and Guthrie, 1984). Furthermore, their usage tends to increase because of erosion and cultivation of marginal lands (García-Ruiz, 2010). Yet little attention has been paid to the effects of the coarser fraction on soil hydraulic characteristics, so that the relevant literature is still rather scarce $(\mathrm{Ma}$ 
and Shao, 2008; Novák and Šurda, 2010; Poesen and Lavee, 1994).

Many authors consider that the reduction in volume available for water flow is the only effect of stones on hydraulic conductivity. This hypothesis has led to models linking the hydraulic conductivity of the fine earth to that of the stony soils. They predict a decrease in saturated hydraulic conductivity of stony soil $\left(K_{\mathrm{se}}\right)$ with an increasing volumetric stoniness $\left(R_{\mathrm{V}}\right)$ (Bouwer and Rice, 1984; Brakensiek et al., 1986; Corring and Churchill, 1961; Hlaváčiková and Novák, 2014; Novák and Kňava, 2012; Peck and Watson, 1979; Ravina and Magier, 1984).

However, a number of studies do not observe this simple relationship between the hydraulic conductivity and the stoniness (Zhou et al., 2009; Ma et al., 2010; Russo, 1983; Sauer and Logsdon, 2002) and suggest that other factors, mainly changes in pore size distribution and structure, may play a substantial role in specific situations. Indeed, ambivalent phenomena can intervene simultaneously, which makes the understanding of the effective hydraulic properties of stony soils difficult. The reduced volume available for flow might be partially compensated for by other factors. One compensation factor might be, as pointed out by Ravina and Magier (1984), the creation of large pores in the rock fragments' vicinity. Indeed, the creation of new voids at the stone-fine earth interface could generate preferential flows and hence increase the saturated hydraulic conductivity (Zhou et al., 2009; Cousin et al., 2003; Ravina and Magier, 1984; Sauer and Logsdon, 2002).

These statements define the general context in which our study takes place. The main objectives are (i) to assess the effect of rock fragments on the saturated and unsaturated hydraulic conductivity of soil and (ii) to test the validity of the predictive models that have been proposed in the literature.

\section{Material and methods}

We studied the effect of $R_{\mathrm{V}}$ on saturated and unsaturated hydraulic conductivity by means of laboratory experiments (evaporation and permeability measurements) and numerical simulations involving different amounts and types of coarse fragments. The latter also serve to further investigate the effect of the stone size and shape on the $K_{\mathrm{se}}$.

\subsection{Models predicting soil hydraulic properties of stony soils}

Multiple equations have been proposed to estimate the saturated hydraulic conductivity of stony soil $\left(K_{\mathrm{se}}\right)$ from the one of the fine earth $\left(K_{\mathrm{S}}\right)$ assuming that rock fragments only decrease the volume available for water flow. The relative saturated hydraulic conductivity $\left(K_{\mathrm{r}}\right)$ is defined as the ratio between the $K_{\mathrm{se}}$ and the $K_{\mathrm{s}}$. Equations (1) and (2) were derived by Peck and Watson (1979) based on heat transfer theory for a homogeneous medium containing non-conductive spherical and cylindrical inclusions, respectively. Assuming that stones are non-porous and do not alter the porosity of the fine earth, Ravina and Magier (1984) approximated the $K_{\mathrm{r}}$ to the volumetric percentage of fine earth (Eq. 3). Based on empirical relations, Brakensiek et al. (1986) proposed a similar equation, but involving the mass fraction of the rock fragments instead of the volumetric fraction (Eq. 4). On the basis of numerical simulations, Novák et al. (2011) proposed to describe the $K_{\mathrm{se}}$ of stony soils as a linear function of the $R_{\mathrm{v}}$ and a parameter that incorporates the hydraulic resistance of the stony fraction (Eq. 5).

$K_{\mathrm{r}}=\frac{2\left(1-R_{\mathrm{V}}\right)}{2+R_{\mathrm{V}}}($ Peck and Watson , 1979, for spherical stones $)$

$K_{\mathrm{r}}=\frac{\left(1-R_{\mathrm{V}}\right)}{1+R_{\mathrm{V}}}($ Peck and Watson , 1979, for cylindrical stones $)$

$K_{\mathrm{r}}=\left(1-R_{\mathrm{v}}\right)($ Ravina and Magier, 1984)

$K_{\mathrm{r}}=\left(1-R_{\mathrm{W}}\right)($ Brakensiek et al., 1986)

$K_{\mathrm{r}}=\left(1-a R_{\mathrm{V}}\right)($ Novák et al., 2011)

In the above, $R_{\mathrm{v}}$ is the volumetric stoniness $\left[\mathrm{L}^{3} \mathrm{~L}^{-3}\right] ; R_{\mathrm{W}}$ is the mass fraction of the rock fragments (mass of stones divided by the total mass of the soil containing stones; the stone density is typically $2.5 \mathrm{~g} \mathrm{~cm}^{-3}$ in this case) $\left[\mathrm{M} \mathrm{M}^{-1}\right]$; and $a$ is an empirical parameter that incorporates the hydraulic resistance of the stony fraction considering shape, size, and orientation of inclusions (the recommended value is 1.32 for clay soils according to Novák et al., 2011).

Two major characteristics are widely used to describe the hydraulic properties of unsaturated soil: the water retention curve $\theta(h)$ and the hydraulic conductivity curve $K(h)$. These are both non-linear functions of the pressure head $h$. One of the most commonly used analytical models was introduced by van Genuchten (1980), based on the pore-bundle model of Mualem (1976), and given by:

$$
\begin{aligned}
& S_{\mathrm{e}}(h)=\frac{\theta(h)-\theta_{\mathrm{r}}}{\theta_{\mathrm{s}}-\theta_{\mathrm{r}}}=\left\{\begin{array}{cc}
\left(1+|\alpha h|^{n}\right)^{-m} & \text { if } h<0 \\
1 & \text { if } h \geq 0,
\end{array}\right. \\
& K\left(S_{\mathrm{e}}\right)=K_{\mathrm{s}} S_{\mathrm{e}}^{l}\left[1-\left(1-S_{\mathrm{e}}^{1 / m}\right)^{m}\right]^{2} \text { if } h<0,
\end{aligned}
$$

in which $h$ is the pressure head [L]; $S_{\mathrm{e}}(h)$ is the saturation state $\left[\mathrm{L}^{3} \mathrm{~L}^{-3}\right] ; \theta(h)$ is the volumetric water content $\left[\mathrm{L}^{3} \mathrm{~L}^{-3}\right]$; $\theta_{\mathrm{r}}$ and $\theta_{\mathrm{s}}$ respectively represent the residual and saturated water content $\left[\mathrm{L}^{3} \mathrm{~L}^{-3}\right] ; K_{\mathrm{S}}$ is the saturated hydraulic conductivity $\left[\mathrm{L} \mathrm{T}^{-1}\right]$; and $n[-], l[-]$, and $\alpha\left[\mathrm{L}^{-1}\right]$ are empirical shape parameters $(m=1-1 / n, n>1)$. To extend the hydraulic conductivity curves to stony soils, Hlaváčiková and Novák (2014) propose a simple method assuming that the shape parameters of the van Genuchten-Mualem (VGM) equations $(\alpha, n$, and $l)$ are independent of $R_{\mathrm{v}}$. However, this model relies on assumptions that have not been verified. It might be worth mentioning that there are currently no extensive empirical studies available dealing with the influence of porous inclusions under unsaturated conditions. This gap in existing literature is probably due to experimental issues 
linked with this kind of study: while measuring the potential and the water content of fine earth has become a standard procedure, the opposite is true for soil with rock fragments, especially under transient infiltration processes.

\subsection{Laboratory experiments}

\subsubsection{Sample preparation}

We performed laboratory experiments on disturbed samples (height: $65 \mathrm{~mm}$; diameter: $142 \mathrm{~mm}$ ) containing a mixture of fine earth and coarse inclusions $>10 \mathrm{~mm}$. Two types of inclusions were used: rock fragments (granite) with a diameter between 1 and $2 \mathrm{~cm}$ (1) and spherical glass beads with a diameter of $1 \mathrm{~cm}$ (2) (see Fig. 1). The fine earth is classified as a clay (sand: $26 \%$; silt: $19 \%$; clay: $55 \%$ ).

Before each measurement campaign, the fine earth was first oven-dried for $24 \mathrm{~h}$ at $105^{\circ} \mathrm{C}$ and passed through a $2 \mathrm{~mm}$ sieve. To prepare a sample without any inclusion, the fine earth was compacted layer by layer to get an overall bulk density of $1.51 \mathrm{~g} \mathrm{~cm}^{-3}$ (equal to the mean bulk density of the fine earth measured in situ; Pichault, 2015). For samples containing rock fragments, stones were divided over four layers of soil application and laid on the fine earth bed on their flattest side. The samples were then compacted layer by layer in a way that maintains the same bulk density of fine earth as for samples without inclusions (as a result, the global bulk density of samples varies according to stoniness). Even though the filling and compaction procedure was conducted with precision, it is probably impossible to avoid local bulk density heterogeneity as stones can move and/or soil between stones can be less compacted due to difficult access of the area close to the stone during compaction. The same procedure was to prepare samples containing glass balls. Once the specimen was made, it was placed in a basket containing a thin layer of water for at least $24 \mathrm{~h}$ in order to saturate the soil from below.

\subsubsection{Unsaturated hydraulic conductivity}

\section{Setup description}

We used the evaporation method to determine the unsaturated hydraulic conductivity and the retention curve of a soil sample. The principle of this method is to simultaneously measure the matric head at different depths and the water content of an initially saturated soil sample submitted to evaporation.

The experiments were performed using cylindrical Plexiglas samples of $1 \mathrm{~L}$ (height: $65 \mathrm{~mm}$; diameter: $142 \mathrm{~mm}$ ), perforated at the bottom to allow saturation from below and open to the atmosphere on the upper side to allow evaporation of the soil moisture. Four $24.9 \mathrm{~mm}$ long and $6 \mathrm{~mm}$ diameter ceramic tensiometers (SDEC230) were introduced at 10, 25, 40 , and $55 \mathrm{~mm}$ height, respectively denoted $\mathrm{T} 1$ to $\mathrm{T} 4$ (the reference level is located at the bottom of the sample). Tensiometers are introduced at saturation; a pin with similar di-
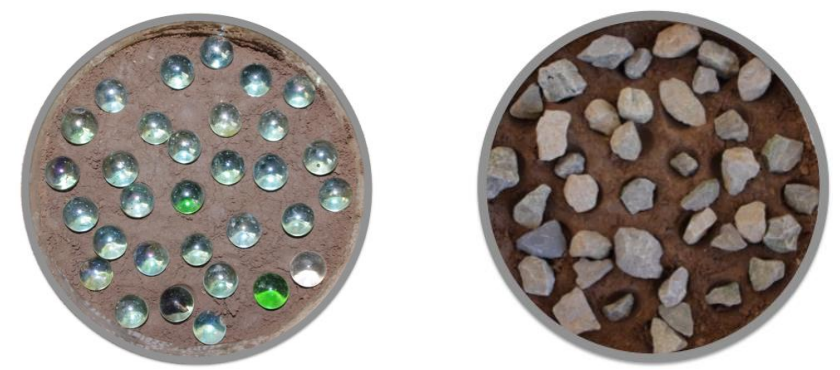

Figure 1. Preparation of disturbed samples containing glass balls (left panel) and gravels (right panel).

mensions is used to facilitate their insertion. In order to avoid preferential flow due to the introduction of the tensiometers on the same vertical axis, each tensiometer was introduced with a horizontal shift of $12^{\circ}$ with respect to the centre of the column. The tensiometers are connected by a tube to a pressure transducer (DPT-100, Deltran). The setup was filled with degassed water. The variation in pressure of the drying soil was recorded every $15 \mathrm{~min}$ by a CR800 logger (Campbell Scientific). Tensions beyond the air entry point were not taken into account. The air entry point refers to the state from which the measured pressure head starts to decrease as bubbles appear and water vapour accumulates (typically $68 \mathrm{kPa}$ in this case).

The total water loss as a function of time was monitored by a balance (OHAUS) with a sensitivity of $0.2 \mathrm{~g}$, an accuracy of $\pm 1 \mathrm{~g}$, and a time resolution of $15 \mathrm{~min}$. A $50 \mathrm{~W}$ infrared lamp was positioned $1 \mathrm{~m}$ above the sample surface to slightly speed up the evaporation process. The light was turned off for the first $24 \mathrm{~h}$ of every experiment, as the evaporation rate is already high in a saturated sample. A measuring campaign lasted until three of the four tensiometers ran dry (the tension sharply drops down to approximately a null value). At the end of the experiment, the sample was oven-dried for $24 \mathrm{~h}$ at $105^{\circ} \mathrm{C}$ to estimate the $\theta$.

\section{Data processing}

A simplified Wind's (1968) method was used to transform matric potential and total weight data over time into the hydraulic conductivity curve (Schindler, 1980, cited by Schindler and Müller, 2006; Schindler et al., 2010). The method is further adapted in order to take into account the data from four tensiometers. The method assumes that the distribution of water tension and water content is linear throughout the soil column. It further linearizes the water tension and the mass changes over time. The time step chosen to process the data is $1 \mathrm{~h}$.

By calculating the hydraulic conductivity based on measurements of two tensiometers and linking it to the corresponding mean matric head, one can evaluate a point of the hydraulic conductivity curve. We used every possible com- 
bination of two tensiometers (six here) to obtain data points for the hydraulic conductivity curve.

Points of the hydraulic conductivity curve obtained at very small hydraulic gradients (defined here as $\nabla H=\frac{\Delta|h|}{\Delta z}-1$ ) were rejected, because large errors occur in the nearsaturation zone due to uncertainties in estimating small hydraulic gradients (Peters and Durner, 2008; Wendroth, 1993). This highlights in turn the necessity of reliable tensiometers to estimate the near-saturated hydraulic conductivity. In the current literature, acceptance limits of the hydraulic gradient vary between 5 and $0.2 \mathrm{~cm} \mathrm{~cm}^{-1}$ (Mohrath et al., 1997; Peters and Durner, 2008; Wendroth, 1993). Using the least restrictive filter criterion (hydraulic gradient $>0.2$ ) requires fine calibration and outstanding performance of the tensiometers. Choosing a more restrictive criterion leads to a larger loss of conductivity points but provides more reliable and robust data. We decided to use a filter criterion that does not consider hydraulic conductivity points higher than the evaporation rate (from 0.1 to $0.2 \mathrm{~cm} \mathrm{day}^{-1}$ in this case), resulting in a lower limit of $1 \mathrm{~cm} \mathrm{~cm}^{-1}$ for the hydraulic gradient.

As pointed out by Wendroth (1993) and Peters and Durner (2008), the main drawback associated with the evaporation experiment is that no estimates of conductivity in the wet range can be obtained due to the typically small hydraulic gradients, so that additional measurements of the $K_{\mathrm{se}}$ should be provided. To do so, we used constant-head permeability experiments (see below). Except for the $K_{\text {se }}$ which is fixed using results from the constant-head permeability experiments, the parameters of the VGM model (1980) (Eq. 7) are obtained by fitting evaluation points from each combination of tensiometers using the so-called "integral method" (Peters and Durner, 2006).

\subsubsection{Saturated hydraulic conductivity}

Constant-head permeability experiments were used to determine the $K_{\text {se }}$ of saturated cylindrical core samples. The flow through the sample is measured at a steady rate under a constant pressure difference. The $K_{\text {se }}$ can thus be derived using the following equation:

$K_{\mathrm{se}}=\frac{V L}{A \Delta H \Delta t}$,

in which $V$ is the volume of discharge $\left[\mathrm{L}^{3}\right], L$ is the length of the permeameter tube [L], $A$ is the cross-sectional area of the permeameter $\left[\mathrm{L}^{2}\right], \Delta H$ is the hydraulic head difference across the length $L[\mathrm{~L}]$, and $\Delta t$ is the time for discharge [T].

The soil sample used for permeability tests has the same size as the one from the evaporation experiment (height: $65 \mathrm{~mm}$; diameter: $142 \mathrm{~mm}$ ). A $2 \mathrm{~cm}$ thick layer of water was maintained on top of the sample thanks to a Mariotte bottle. Water was collected through a funnel in a burette and the volume of discharge $V$ was deduced from measurements
Table 1. Parameters of the van Genuchten equations used in the numerical experiments.

\begin{tabular}{lccccc}
\hline $\begin{array}{l}\theta_{\mathrm{r}} \\
{[-]}\end{array}$ & $\begin{array}{c}\theta_{\mathrm{S}} \\
{[-]}\end{array}$ & $\begin{array}{c}\alpha \\
{\left[\mathrm{cm}^{-1}\right]}\end{array}$ & $\begin{array}{c}n \\
{[-]}\end{array}$ & $\begin{array}{c}l \\
{[-]}\end{array}$ & $\begin{array}{c}K_{\mathrm{Se}} \\
{\left[\mathrm{cm} \mathrm{day}^{-1}\right]}\end{array}$ \\
\hline 0.185 & 0.442 & 0.0064 & 2.11 & -0.135 & 2.686 \\
\hline
\end{tabular}

after 30 and $210 \mathrm{~min}$ after the beginning of the experiment $(\Delta t=180 \mathrm{~min})$.

\subsection{Numerical simulations}

The HYDRUS-2D software was used to simulate water flow in variably saturated porous stony soils. HYDRUS-2D solves the two-dimensional Richards equation using the Galerkin finite-element method.

All the performed simulations assumed that rock fragments were non-porous so that "no-flux" boundaries conditions were specified along the stones' limits. Since we mimic the laboratory setup, rock fragments were modelled as circular inclusions. The soil domain over which simulations were performed had the same dimensions as the longitudinal section of the sampling ring used in the laboratory experiments $(14 \times 6.5 \mathrm{~cm})$. We considered the 2-D fraction of stoniness equal to the volumetric fraction. The parameters of fine earth used in the simulations come from the fitting of the hydraulic conductivity and water retention curves obtained in our laboratory experiments on stone-free samples (Table 1).

As a general rule, the hydraulic conductivity of a heterogeneous medium tends to be higher for 3-D than for 2-D simulations (Dagan, 1993). Similarly, for a same level of heterogeneity, the flow will be more hampered using 1-D rather than 2-D simulations. In the present study, we performed 2D simulations: the quantitative and qualitative conclusions from these experiments can be only extended to the third dimension for their corresponding 3-D form with an infinitely long axis.

\subsubsection{Unsaturated hydraulic conductivity}

We complemented our experimental evaporation results with an equivalent virtual evaporation experiment. The top boundary of the virtual sample was submitted to an evaporation rate $q$ of $0.1 \mathrm{~cm} \mathrm{day}^{-1}$ over 14 days. No fluxes were allowed across other boundaries. The calculation method applied to the output data was similar to the laboratory evaporation experiment, except that the conductivity and pressure head estimations resulted from two observation nodes placed at the top and the bottom of the profile instead of from four tensiometers. We are aware that these choices are debatable: on the one hand, numerical instabilities are more plausible at the limits of the sample and, on the other hand, the use of bigger samples than conventionally used $(6.5 \mathrm{~cm}$ height $)$ might reduce the accuracy of the evaporation method (see Peters et 
al., 2015). However, we did keep the observation nodes on the edges and the larger sample size for the following reasons. Firstly, we observed more changes in hydraulic gradient near stones. As small variations in the hydraulic gradient can lead to substantial changes in the hydraulic conductivity estimates, we chose to place observation nodes out of the influence of one specific inclusion. This difficulty, especially at high stone contents, is the reason why the nodes are not situated inside of the sample volume but rather at the edges. Secondly, we checked whether the pressure head was linearly distributed across the soil profile, which was the case. Finally, as we are studying clayey soils, and as we are considering a pressure head range between $\mathrm{pF} 1.5$ and 2.5, these assumptions are likely to be fair (Peters et al., 2015).

As the relative mass balance error was large at the beginning of the simulations, we only started considering values from the moment when this relative error was lower than $5 \%$. This validation criterion was set arbitrarily, based on the comparison between evaluation points from the simulation of the evaporation experiment on stone-free samples and the expected values obtained from the inputs of the simulation. The hydraulic conductivity curve was obtained fitting the discrete conductivity data plus the simulated saturated hydraulic conductivity using the integral method (Peters and Durner, 2006), just like we did for the laboratory experiment.

\subsubsection{Saturated hydraulic conductivity}

The $K_{\text {se }}$ was determined using a numerical constant-head permeability simulation. We simulated a steady-state water flow of a saturated soil profile, with a constant head of $10 \mathrm{~cm}$ applied on the upper boundary. The bottom boundary of the column was defined as a "seepage face", which means that water starts flowing out as soon as the soil at the boundary reaches saturation. The calculation method applied to the output data was identical to the permeability experiment.

\subsection{Treatments}

Table 2 presents a scheme of all the performed experiments. We duplicated each laboratory experiment with similar numerical simulations.

We first studied the effect of $R_{\mathrm{V}}$ on unsaturated hydraulic properties using laboratory experiments and numerical simulations. In the laboratory approach, we performed evaporation experiments on samples containing (i) fine earth only and (ii) on others with rock fragments (1) at a $R_{\mathrm{V}}$ of $20 \%$. Two replications per treatment were performed (four measurement campaigns in total). For the numerical approach, simulations of the evaporation experiment were done on homogeneous soil (without stones) and on soil with a $R_{\mathrm{v}}$ of 10 , 20 , and $30 \%$. Having fewer time and practical constraints in the numerical simulation, we added an increasing $R_{\mathrm{v}}$ to observe the evolution of the hydraulic conductivity curve. Simulations were performed on soil samples containing 12 reg- 
ularly distributed stones. One can notice that no investigations of the unsaturated properties with coarse fragments above $30 \%$ of $R_{\mathrm{v}}$ were performed. Indeed, given that small variations in the hydraulic gradient can lead to substantial changes in the hydraulic conductivity estimates, the tensiometers should be ideally positioned out of the direct influence of one particular stone in order to obtain generalizable results. This implies the need for relatively low stone contents $(<30 \%$ according to Zimmerman and Bodvarsson, 1995).

Then, to study the relationship between saturated hydraulic conductivity, $K_{\mathrm{se}}$, and $R_{\mathrm{v}}$, we performed five replications of four volumetric stone fractions $(0,20,40$, and $60 \%)$ with rock fragments (1). We also tested a second type of inclusions, glass spheres (2), with a $R_{\mathrm{v}}$ of $20 \%$ (1 replication). The first setup with rock fragments was concomitant with the one with glass spheres. Then, the four supplementary replications with rock fragments were processed for the different volumetric fractions altogether: between replications the soil was oven-dried for $24 \mathrm{~h}$ at $105^{\circ} \mathrm{C}$ and passed through a $2 \mathrm{~mm}$ sieve. Numerical permeability simulations were also performed involving 12 circular regularly distributed inclusions for the same $R_{\mathrm{V}}(0,20,40$, and $60 \%)$.

Finally, we used supplementary numerical simulations to investigate the effect of the inclusion shape and size on $K_{\mathrm{se}}$. To do so, simulations of the permeability test were performed on soil containing stones of five different shapes: circular, upward equilateral triangle, downward equilateral triangle, rectangle on its shortest side $(\mathrm{L} \times 1.5 \mathrm{~L})$, and rectangle on its longest side $(1.5 \mathrm{~L} \times \mathrm{L})$ with an $R_{\mathrm{V}}$ of 10,20 , and $30 \%$. We first performed simulations on soil containing only one centred inclusion. We also performed permeability simulations on soil containing 12 and 27 regularly distributed inclusions (for each $R_{\mathrm{V}}$ ).

\section{Results and discussion}

In the following, results from laboratory experiments and numerical simulations will be compared to the predictions of the different models presented in Sect. 2.1. The $K_{\text {se }}$ will be represented by the median value predicted by the five models linking the properties of fine earth to the ones of stony soil (Eqs. 1 to 5). This will be referred to as "results from the $K_{\text {se }}$ predictive models" in the following and will be graphically represented by dotted lines. The same predictive models assume that the shape parameters of the VGM equations ( $n$, $l$, and $\alpha$ ) do not depend on the stoniness, as suggested by Hlaváčiková and Novák (2014). As mentioned above, unsaturated functions of stony soils have been barely studied. We will compare results from unsaturated experiments and numerical simulations to predictive models results following this assumption.

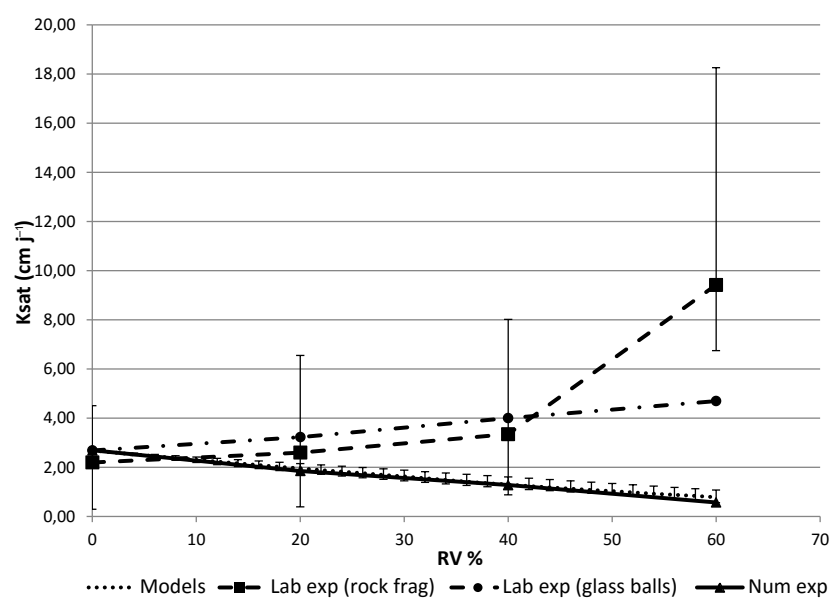

Figure 2. $K_{\mathrm{se}}$ depending on $R_{\mathrm{V}}$ obtained from laboratory experiments, numerical simulations with 12 circular inclusions, and the predictive models (the bars show the maximum and minimum intervals around the median predicted by these models).

\subsection{Effect of stones on saturated hydraulic conductivity}

Figure 2 shows the relationship between the saturated hydraulic conductivity $\left(K_{\mathrm{se}}\right)$ and the volumetric stone content $\left(R_{\mathrm{v}}\right)$ obtained from the constant-head permeability tests for laboratory experiments and numerical simulation (12 circular inclusions). The figure also depicts the median $K_{\text {se }}$ of the predictive models (dashed line) and the bars show the $95 \%$ intervals around the median predicted by these models.

The models predict a decreasing $K_{\mathrm{se}}$ for an increasing $R_{\mathrm{v}}$. The numerical simulations show a decrease in $K_{\mathrm{se}}$ with an increasing $R_{\mathrm{v}}$, similar to the predictive models. Looking at the average curve obtained with our five replications (Fig. 2), we observe an overall increase between a $R_{\mathrm{V}}$ of 0 and $60 \%$, with this global trend being observed for each replication individually (Fig. 3). Statistically speaking, there are significant differences between $K_{\mathrm{se}}$ at a $R_{\mathrm{V}}$ of 0 and $60 \%$ and between $K_{\text {se }}$ at a $R_{\mathrm{v}}$ of 20 and $60 \%$. However, at low stone content, we observe a local decrease in $K_{\mathrm{se}}$ for some replications. For example, for the first replication (Gravels 1, Fig. 3) $K_{\text {se }}$ decreases until a $R_{\mathrm{v}}$ of $20 \%$ and then $K_{\mathrm{se}}$ begins to increase. For the second replication (Gravels 2, Fig. 3), the $K_{\text {se }}$ increases from a $R_{\mathrm{v}}$ of 0 to $20 \%$ and then decreases at a $R_{\mathrm{v}}$ of $40 \%$. Analogous permeability tests conducted by Zhou et al. (2009) showed a similar behaviour: the $K_{\mathrm{se}}$ initially decreases at low rock content to a minimum value at $R_{\mathrm{v}}=22 \%$, and then at higher $R_{\mathrm{v}} K_{\mathrm{se}}$ tends to increase with $R_{\mathrm{v}}$. Other laboratory tests carried out by Ma et al. (2010) displayed a larger $K_{\mathrm{se}}$ at $R_{\mathrm{v}}=8 \%$ than the one of the fine earth alone. While carrying out in situ infiltration tests, Sauer and Logsdon (2002) measured higher $K_{\mathrm{se}}$ with increasing $R_{\mathrm{v}}$ but decreasing $K$ with increasing $R_{\mathrm{v}}$ under unsaturated conditions (and particularly at $h=-12 \mathrm{~cm}$ ). These considerations suggest that the relationship between $K_{\mathrm{se}}$ and $R_{\mathrm{v}}$ proposed by 


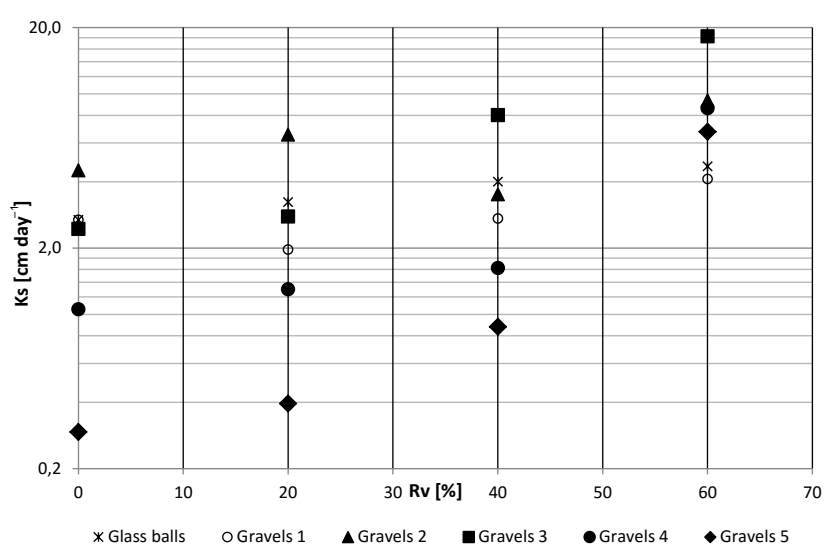

Figure 3. $K_{\mathrm{se}}$ depending on $R_{\mathrm{V}}$ obtained from laboratory experiments with gravels (five replications) and glass balls (one replication).

the predictive models simplifies reality to a great extent. These contradictory results suggest that the variation in $K_{\text {se }}$ depends on different factors that can counteract the reduction in the volume available for water flow. One possible explanation of our observations has been pointed out by Ravina and Magier (1984), who directly observed large voids by cutting across a stony clay soil sample after its compaction, presumably due to translational displacement of densely packed fragments. This compaction of a saturated sample creates voids near the stone surface and hence increases $K_{\mathrm{se}}$ with an increasing $R_{\mathrm{V}}$. Our packing procedure, demanding the compaction of the sample layer by layer, could lead to the same kind of phenomena observed by Ravina and Magier (1984). Moreover, we have to keep in mind that these elements are very likely to have a different impact depending on soil texture, which was clay for both studies.

Glass beads were used to check the influence of rock characteristics on our conclusions about $K_{\mathrm{se}}$. Since results with glass beads show a trend similar to the five replications with rock fragments, we infer that it is not the rock fragment itself that produces bigger $K_{\mathrm{se}}$ but rather the presence of a certain volume of inclusions. In addition, the variation observed between the trends of the curves with rock fragments and glass beads could be due to the inner variation in the hydraulic properties of samples, but it could suggest as well that $K_{\text {se }}$ depends on the shape and the roughness of the inclusions. Nevertheless, we can only see the combined effect of these factors in this experiment. This leaves the understanding of the major drivers of the $K_{\mathrm{se}}$ and their relative importance unclear. These elements are further investigated through numerical simulations.

Besides the observed increase in $K_{\text {se }}$ with rock content, we can also observe a decrease in $K_{\text {se }}$ between replications (see Fig. 3). In fact, as mentioned above, the global trend of increasing $K_{\mathrm{se}}$ is observed for each replication individually, but packing procedure seems to have a large impact on
Table 3. Results from the investigation of the inclusion size and shape with regard to the saturated hydraulic conductivity by means of numerical simulations ( $n$ is the number of inclusions simulated in the profile for the corresponding $R_{\mathrm{V}}$ ).

\begin{tabular}{|c|c|c|c|c|}
\hline \multirow[t]{2}{*}{$R_{\mathrm{V}}$} & \multirow[t]{2}{*}{ Shape } & \multicolumn{3}{|c|}{$\begin{array}{c}\text { Relative saturated } \\
\text { hydraulic conductivity }\end{array}$} \\
\hline & & $n=1$ & $n=12$ & $n=27$ \\
\hline \multirow{5}{*}{$10 \%$} & $\mathbf{\square}$ & 0.88 & 0.88 & 0.88 \\
\hline & • & 0.84 & 0.83 & 0.82 \\
\hline & $\Delta$ & 0.80 & 0.79 & 0.78 \\
\hline & & 0.80 & 0.79 & 0.78 \\
\hline & $\diamond$ & 0.84 & 0.83 & 0.82 \\
\hline \multirow{5}{*}{$20 \%$} & $\square$ & 0.76 & 0.71 & 0.68 \\
\hline & $\bullet$ & 0.73 & 0.69 & 0.65 \\
\hline & $\Delta$ & 0.67 & 0.63 & 0.54 \\
\hline & $\nabla$ & 0.67 & 0.63 & 0.54 \\
\hline & $\diamond$ & 0.66 & 0.61 & 0.54 \\
\hline \multirow{5}{*}{$30 \%$} & 口 & 0.70 & 0.60 & 0.55 \\
\hline & • & 0.64 & 0.58 & 0.48 \\
\hline & $\Delta$ & 0.59 & 0.50 & 0.46 \\
\hline & $\nabla$ & 0.59 & 0.50 & 0.47 \\
\hline & $\diamond$ & 0.56 & 0.48 & 0.31 \\
\hline
\end{tabular}

results too. There are significant differences $(p<0.05)$ between replication 2 and replication 5, the last one presenting lower $K_{\mathrm{se}}$. The drying and wetting cycles and/or the sieving influence the hydrodynamic behaviour of soil fraction since the effect decreases when $R_{\mathrm{v}}$ increases. This underlines the effect of soil texture and is an important aspect to take into account in future studies.

\subsection{Effect of the stone size and shape on the saturated hydraulic conductivity}

To investigate the effect of the size of the inclusions and their shape on $K_{\text {se }}$ separately from other factors of variation, we performed constant-head permeability simulations on samples containing 1,12 , and 27 inclusions of various shapes, for a $R_{\mathrm{v}}$ of 10,20 , and $30 \%$. Table 3 illustrates the tendency of the effects and their respective factors.

Table 3 presents the $K_{\mathrm{r}}$ for different sizes of circular inclusions and increasing overall stone content $\left(R_{\mathrm{V}}\right)$. When the size of the inclusions decreases (when the number of inclusions increases for a same $R_{\mathrm{v}}$ ), the $K_{\mathrm{r}}$ tends to decrease. An interaction between the $R_{\mathrm{V}}$ and the size of inclusion can be observed: the effect of size is more marked with a higher $R_{\mathrm{V}}$. For example, the decrease in $K_{\mathrm{r}}$ between 1 and 27 circular inclusions is limited to $2 \%$ for a $R_{\mathrm{v}}$ of $10 \%$ but rises up to $25 \%$ for a $R_{\mathrm{v}}$ of $30 \%$. A similar behaviour is observed with simulations for different shapes of inclusions. One could think that this observation is directly related to change in the minimal cross section for water flow. Figure 4 plots $K_{\mathrm{r}}$ as a func- 


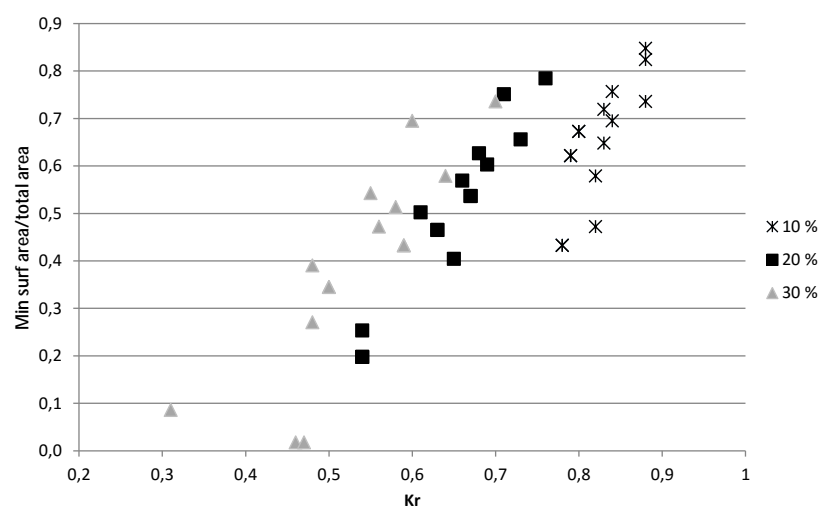

Figure 4. Relationship between minimum surface area and $K_{\mathrm{r}}$ for different $R_{\mathrm{V}}$.

tion of the ratio between minimal surface area and total surface area. Minimal surface area was calculated as the sample width minus the maximal bulk of stones. Even if we observe a linear trend between these two variables, the relationship is not perfect as we could expect with numerical simulations, supporting the hypothesis that the reduction in the cross section is not the only factor for $K_{\mathrm{r}}$ variations. These statements support the findings of Novák et al. (2011): the smaller the stones, the higher the resistance to flow at a given stoniness. We suggest the decrease in $K_{\mathrm{se}}$ is due to a combination of the two following phenomena. The first one is the overlapping of the influence zone of each inclusion, causing further reduction in $K_{\mathrm{r}}$. The concept of overlapping influence zones was first proposed by Peck and Watson (1979) to explain higher decrease in the hydraulic conductivity of stones very close to each other in comparison to isotropically distributed stones. The second phenomenon could be that, for a given $R_{\mathrm{v}}$, the contact area between stones and fine earth is higher for small stones than for bigger ones. Hence, a higher tortuosity can be responsible for a lower flow rate.

The shape of the inclusions also has a visible impact on $K_{\mathrm{r}}$. For a fixed number of inclusions, the $K_{\mathrm{r}}$ is higher with rectangular inclusions on their shortest side and smaller with rectangular inclusions on their longest side. Circular inclusions provoke a smaller reduction than triangular inclusions. The orientation of the triangles does not have a pronounced effect on $K_{\mathrm{r}}$. Here again, we observe a stronger effect of the size for higher stoniness. As an illustration, the decrease in $K_{\mathrm{r}}$ between circular and triangular inclusions is limited to $5 \%$ for a $R_{\mathrm{V}}$ of $10 \%$ but rises up to $14 \%$ for a $R_{\mathrm{V}}$ of $30 \%$. A similar behaviour is observed with simulations including either 1 or 27 fragments.

Considering a fixed $R_{\mathrm{V}}$ of $20 \%$ (see Table 3 ), the effect of the shape of the inclusions depends on their size. For example, the decrease in $K_{\mathrm{r}}$ between rectangular inclusions positioned on their longest and shortest sides is limited to $13 \%$ for samples containing one inclusion only, while it is as high as $21 \%$ for samples containing 27 inclusions. Inversely, the effect of the size of inclusions also depends on their shape. This effect is higher for triangular and rectangular inclusions positioned on their longest side, with a $K_{\mathrm{r}}$ decrease between 1 and 27 inclusions of 23 and $18 \%$, respectively. This effect is less significant for circular inclusions, as well as for rectangular inclusions positioned on their shortest sides. The associated $K_{\mathrm{r}}$ decrease between 1 and 27 inclusions is 11 and $10 \%$, respectively.

The median value of $K_{\mathrm{r}}$ predicted by the models for a $R_{\mathrm{V}}$ of $20 \%(0.73)$ is similar to the simulated $K_{\mathrm{r}}$ for samples containing only one spherical inclusion (Table 3 ). The $K_{\mathrm{r}}$ predicted by the models is always higher than the $K_{\mathrm{r}}$ determined by the simulations, except for soils containing one inclusion on its shortest side. This can be a side effect of 2D simulations versus 3-D measurements. Nevertheless, the numerical simulations show that the shape and the size of inclusions may have an effect on $K_{\mathrm{se}}$, which is usually neglected by the current predictive models. In general there is a concordance between models and simulations, whatever the shape and orientation of stones. This strengthens our hypothesis that macropore creation or heterogeneity of bulk density close to the stones can occur and influence $K_{\mathrm{se}}$. Indeed, numerical simulations cannot simulate the creation of voids, unless we create them manually and subjectively in the domain.

Eventually, we hypothesize that, from a certain $R_{\mathrm{v}}$ onwards (the exact $R_{\mathrm{v}}$ value depending on the sampling procedure and the shape and roughness of inclusions, as well as soil texture), stoniness is at the origin of a modification of pore size distributions and of a more continuous macropore system at the stone interface. This macropore system could overcome the other drivers reducing $K_{\text {se }}$.

\subsection{Effect of stones on unsaturated hydraulic conductivity}

Figure 5 represents the hydraulic conductivity curves obtained from the permeability and evaporation simulations for different stoniness $\left(R_{\mathrm{V}}=0,10,20\right.$ and $\left.30 \%\right)$ as well as results predicted by the models for the corresponding $R_{\mathrm{v}}$. The hydraulic conductivity curves from the predictive models and from the numerical simulations match hydraulic conductivity decreases for increasing $R_{\mathrm{v}}$. According to these simulations, hydraulic conductivity in the unsaturated zone is well defined using a correct $K_{\text {se }}$ and shape parameters do not depend on the stoniness. But this is not surprising since predictive models and numerical simulations rely on the same assumptions, i.e. imperviousness of stones and an identical porosity distribution of fine earth. As a result, these elements do not prove that shape parameters do not depend on the stoniness.

Figure 6 represents the hydraulic conductivity curves obtained from laboratory experiments on stone-free samples and on samples with a $R_{\mathrm{V}}$ of $20 \%$ as well as the results predicted by the models for a $R_{\mathrm{V}}$ of $20 \%$. Even though the data points are dispersed, those coming from the evaporation 


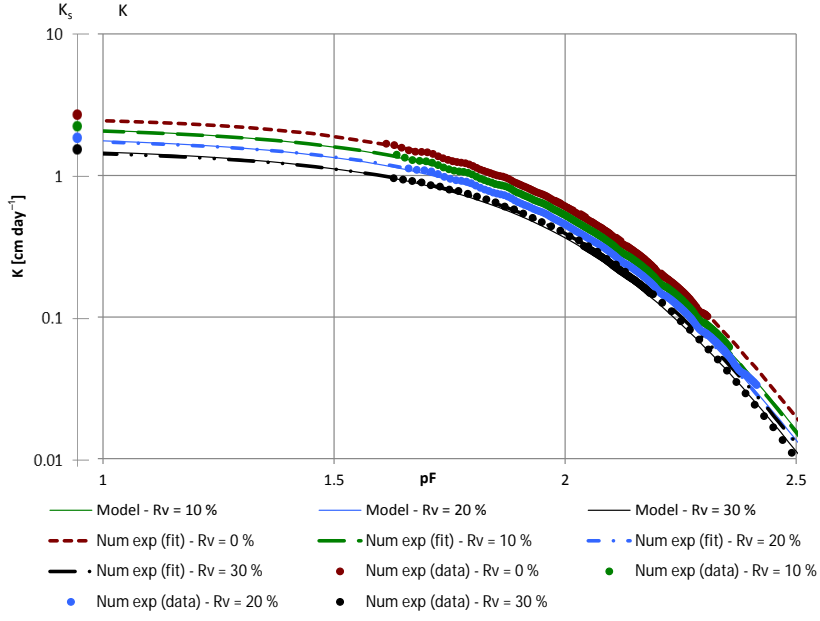

Figure 5. Hydraulic conductivity curves obtained from numerical experiments (data and fit for $R_{\mathrm{V}}=0,10,20,30 \%$ ) and results predicted by the models for the corresponding $R_{\mathrm{V}}$.

experiments measured on stony samples are globally lower and slightly more flattened than the ones measured on stonefree samples. This suggests that stones decrease unsaturated hydraulic conductivity. However, it must be noted that we do not have unsaturated $K$ data for higher stone contents, whereas for $K_{\mathrm{se}}$ the effect of stoniness becomes more obvious for $R_{\mathrm{V}}>20 \%$. In order to draw final conclusions, it might be necessary to find a way to conduct evaporation experiments for higher stone contents.

In the numerical simulations, the presence of stones reduces the hydraulic conductivity in the same way as predicted by the models, regardless of what the suction was. Similarly, the laboratory experiments suggest that stones reduce the unsaturated hydraulic conductivity, while laboratory experiments in saturated conditions indicated that stones content might increase the $K_{\mathrm{se}}$. These elements support the hypothesis of the macropore creation: according to the wellknown law of Jurin (1717), pores through which water will flow depend on both the pore size distribution and the effective saturation. Consequently, flow in the macropore system will only be "activated" in the near-saturation zone, while small pores will only be drained at high suction. Therefore, we could hypothesize that stones are always expected to decrease the hydraulic conductivity at low effective saturation states. However, under saturated conditions, the relationship between $R_{\mathrm{v}}$ and $K_{\text {se }}$ seems to be less trivial and requires further investigations considering soil texture and stone characteristics.

\section{Conclusion}

Determining the effect of rock fragments on soil hydraulic properties is a major issue in soil physics and in the study of fluxes in soil-plant-atmosphere systems in general. Several

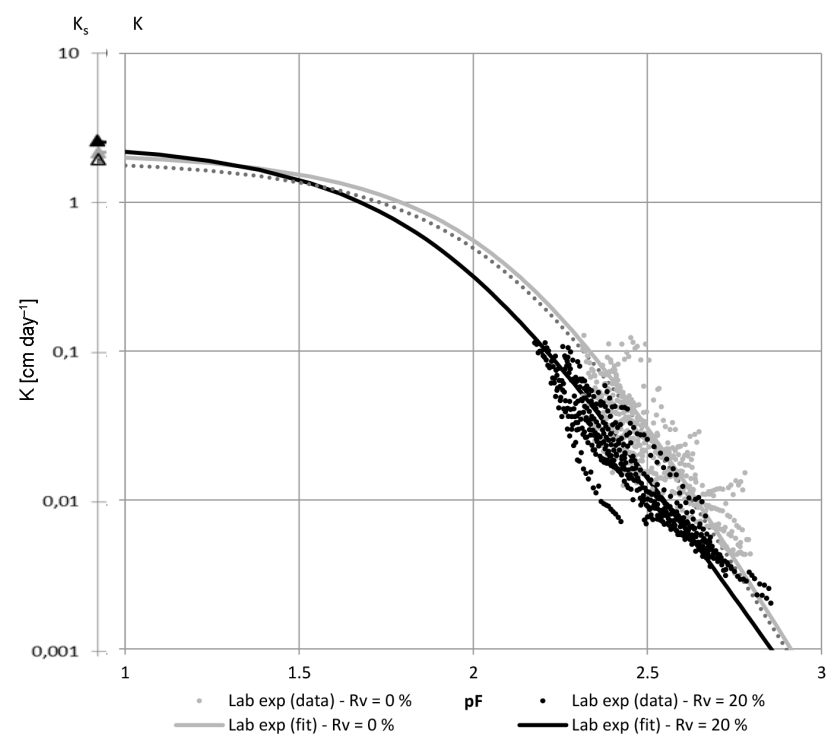

Figure 6. Hydraulic conductivity curves obtained from laboratory experiments (data and fit for $R_{\mathrm{V}}=0$ and $20 \%$ ) and results predicted by the models for a $R_{\mathrm{V}}$ of $20 \%$ (dotted line). Triangles are saturated hydraulic conductivity: closed is measured with black for the stony and grey for the fine earth, and open is predicted by the model (median value of the models).

models aim at linking the hydraulic properties of fine earth to those of stony soil. Many of them assume that the only effect of stones is to reduce the volume available for water flow. We tested the validity of such models with various complementary experiments.

Our results suggest that it may be ill-founded to consider that stones only reduce the volume available for water flow. First, we observed that, contradictory to the predictive models, the saturated hydraulic conductivity of the clayey soil of this study increases with stone content. Furthermore, we pointed out several other potential drivers influencing $K_{\mathrm{se}}$ which are not considered by these $K_{\text {se }}$ predictive models. We observed that, for a given stoniness, the resistance to flow is higher for smaller inclusions than for bigger ones. We explain this tendency by an overlap of the influence zones of each stone combined with a higher tortuosity of the flow path. We also pointed out the shape of stones as a factor affecting the hydraulic conductivity of the soil. We showed that the effect of the shape depends on the inclusion size and inversely that the effect of inclusion size depends on its shape. Finally, our results converge to the assumption that this contradictory variation in $K_{\mathrm{se}}$ could find its origin at the creation of voids at the stone-fine earth interface as pointed out by Ravina and Magier (1984). Even if the very mechanisms behind these observations remain unclear, they seem to strongly depend on $R_{\mathrm{v}}$, shape, and roughness of inclusions. However, as we conducted these experiments on a specific clay soil only, and given the fact that structural modifications are textural dependent, our results cannot be extrapolated to other soil textures 
without similar experiments. Finally, as we worked with disturbed samples, our results do not include quantification of natural phenomena such as swelling and shrinking that occur naturally for clay soils.

These findings suggest that the aforementioned predictive models are not appropriate in all cases, particularly under saturated conditions. Models should take into account the counteracting factors, notably size and shape of stones. However, further investigations are required in order to explore the hydraulic properties of stony soils and to develop new models or adapt the existing ones. The direct observation of the porosity of undisturbed stony samples using X-ray computed tomography or magnetic resonance imaging could firstly confirm and then help to better understand the mechanism of supposed voids' creation at the stone-fine earth interface. However, under unsaturated conditions, these considerations should be more nuanced, as both numerical simulations and laboratory experiments corroborate the general trends from the predictive models. Finally, similar analyses should be conducted in view of determining the effect of the fine earth texture on the drivers of hydraulic properties as pointed out throughout our research.

\section{Data availability}

The laboratory measurements of this study are available at doi:10.5281/zenodo.32661.

Acknowledgements. We thank Stephane Becquevort of the soil physics lab for his support in setting up the experiments.

Edited by: J. Vanderborght

Reviewed by: D. Ma, W. Durner, and one anonymous referee

\section{References}

Bouwer, H. and Rice, R. C.: Hydraulic Properties of Stony Vadose Zones, Ground Water, 22, 696-705, 1984.

Brakensiek, D. L., Rawls, W. J., and Stephenson, G. R.: Determining the Saturated Hydraulic Conductivity of a Soil Containing Rock Fragments 1, Soil Sci. Soc. Am. J., 50, 834-835, 1986.

Buchter, B., Hinz, C., and Flühler, H.: Sample size for determination of coarse fragment content in a stony soil, Geoderma, 63, 265-275, 1994.

Corring, R. L. and Churchill, S. W.: Thermal conductivity of heterogeneous materials, Chem. Eng. Prog., 57, 53-59, 1961.

Cousin, I., Nicoullaud, B., and Coutadeur, C.: Influence of rock fragments on the water retention and water percolation in a calcareous soil, Catena, 53, 97-114, 2003. Dagan, G.: Higherorder correction of effective permeability of heterogeneous isotropic formations of lognormal conductivity distribution, Transp. Porous. Med., 12, 279-290, 1993.

García-Ruiz, J. M.: The effects of land uses on soil erosion in Spain: A review, Catena, 81, 1-11, 2010.
Gusev, Y. and Novák, V.: Soil water - main water resources for terrestrial ecosystems of the biosphere, J. Hydrol. Hydromech. Slovak Republ., 55, 3-15, 2007.

Hlaváčiková, H. and Novák, V.: A relatively simple scaling method for describing the unsaturated hydraulic functions of stony soils, J. Plant Nutr. Soil Sci., 177, 560-565, 2014.

Jurin, J.: An Account of Some Experiments Shown before the Royal Society; With an Enquiry into the Cause of the Ascent and Suspension of Water in Capillary Tubes, Philos. Trans., 30, 739-747, 1717.

Ma, D. H. and Shao, M. A.: Simulating infiltration into stony soils with a dual-porosity model, Eur. J. Soil Sci., 59, 950-959, 2008.

Ma, D. H., Zhang, J. B., Shao, M. A., and Wang, Q. J.: Validation of an analytical method for determining soil hydraulic properties of stony soils using experimental data, Geoderma, 159, 262-269, 2010.

Miller, F. T. and Guthrie, R. L.: Classification and distribution of soils containing rock fragments in the United States, Eros. Product. Soils Contain. Rock Fragm. SSSA Spec Publ., 13, 1-6, 1984.

Mohrath, D., Bruckler, L., Bertuzzi, P., Gaudu, J. C., and Bourlet, M.: Error Analysis of an Evaporation Method for Determining Hydrodynamic Properties in Unsaturated Soil, Soil Sci. Soc. Am. J., 61, 725-735, 1997.

Mualem, Y.: A new model for predicting the hydraulic conductivity of unsaturated porous media, Water Resour. Res., 12, 513-522, 1976.

Novák, V. and Kňava, K.: The influence of stoniness and canopy properties on soil water content distribution: simulation of water movement in forest stony soil, Eur. J. Forest Res., 131, 17271735, 2012.

Novák, V. and Šurda, P.: The water retention of a granite rock fragments in High Tatras stony soils, J. Hydrol. Hydromech., 58, 181-187, 2010.

Novák, V., Kňava, K., and Šimůnek, J.: Determining the influence of stones on hydraulic conductivity of saturated soils using numerical method, Geoderma, 161, 177-181, 2011.

Peck, A. J. and Watson, J. D.: Hydraulic conductivity and flow in non-uniform soil, Workshop on Soil Physics and Field Heterogeneity, CSIRO Div. Environ. Mech., Canberra, 1979.

Peters, A. and Durner, W.: Improved estimation of soil water retention characteristics from hydrostatic column experiments, Water Resour. Res., 42, W11401, doi:10.1029/2006WR004952, 2006.

Peters, A. and Durner, W.: Simplified evaporation method for determining soil hydraulic properties, J. Hydrol., 356, 147-162, 2008.

Peters, A., Iden, S. C., and Durner, W.: Revisiting the simplified evaporation method: Identification of hydraulic functions considering vapor, film and corner flow, J. Hydrol., 527, 531-542, 2015.

Pichault, M.: Characterization of stony soil's hydraulic properties and elementary volume using field, laboratory and numerical experiments, MsC thesis, ULg Gembloux Agro Bio Tech, p. 73, 2015.

Poesen, J. and Lavee, H.: Rock fragments in top soils: significance and processes, Catena, 23, 1-28, 1994.

Ravina, I. and Magier, J.: Hydraulic Conductivity and Water Retention of Clay Soils Containing Coarse Fragments, Soil Sci. Soc. Am. J., 48, 736-740, 1984.

Russo, D.: Leaching Characteristics of a Stony Desert Soil 1, Soil Sci. Soc. Am. J., 47, 431-438, 1983. 
Sauer, T. J. and Longsdon, S. D.: Hydraulic and physical properties of stony soils in a small watershed, Soil Sci. Soc. Am. J., 66, 1947-1956, 2002.

Schindler, U.: Ein Schnellverfahren zur Messung der Wasserleitfähigkeit im teilgesättigten Boden an Stechzylinderproben, Arch. Acker- Pflanzenb. Bodenkd., 24, 1-7, 1980.

Schindler, U. and Müller, L.: Simplifying the evaporation method for quantifying soil hydraulic properties, J. Plant Nutr. Soil Sci., 169, 623-629, 2006.

Schindler, U., Durner, W., von Unold, G., and Müller, L.: Evaporation Method for Measuring Unsaturated Hydraulic Properties of Soils: Extending the Measurement Range, Soil Sci. Soc. Am. J., 74, 1071-1083, 2010.

van Genuchten, M. T.: A Closed-form Equation for Predicting the Hydraulic Conductivity of Unsaturated Soils, Soil Sci. Soc. Am. J., 44, 892-898, 1980.
Wendroth, E.: Reevaluation of the evaporation method for determining hydraulic functions in unsaturated soils, Soil Sci. Soc. Am. J., 57, 1436-1443, 1993.

Wind, G. P.: Capillary conductivity data estimated by a simple method, 181-191, in: Water in the unsaturated zone, edited by: Rijtema, P. E. and Wassink, H., Proc. Wageningen Symp., 1, 1923 June 1968, Int. Assoc. Sci. Hydrol. Publ., Gentbrugge, the Netherlands, 1968.

Zhou, B. B., Shao, M. A. and Shao, H. B.: Effects of rock fragments on water movement and solute transport in a Loess Plateau soil, Comptes Rendus Geosci., 341, 462-472, 2009.

Zimmerman, R. W. and Bodvarsson, G. S.: The effect of rock fragments on the hydraulic properties of soils, Lawrence Berkeley Lab., CA, USA, USDOE, Washington, D.C., USA, 1995. 